\title{
Case Report \\ Postcoital Internal Carotid Artery Dissection Presenting as Isolated Painful Horner Syndrome: A Case Report
}

\author{
Eren Gozke, Hilal Tastekin Toz, Pinar Kahraman Koytak, and Funda Alparslan \\ Department of Neurology, FSM Teaching and Research Hospital, 34752 Istanbul, Turkey \\ Correspondence should be addressed to Eren Gozke; egozke@hotmail.com
}

Received 11 January 2013; Accepted 31 January 2013

Academic Editors: P. Berlit, J. L. González-Gutiérrez, J. C. Kattah, and Y. Wakabayashi

Copyright (C) 2013 Eren Gozke et al. This is an open access article distributed under the Creative Commons Attribution License, which permits unrestricted use, distribution, and reproduction in any medium, provided the original work is properly cited.

\begin{abstract}
Postcoital artery dissection is a rare condition. Here we report a 40-year-old male patient with painful Horner syndrome related to postcoital internal carotid artery (ICA) dissection. In neurologic examination of the patient, semiptosis, enophthalmus, and myosis were observed on the left side. There were no carotid bruits. On T1-weighted and fat-suppressed cranial MRI, hyperintensity consistent with intramural hematoma was observed within cervical and temporal petrous segments of left ICA. On cervical and cranial MRA, marked decrease in the calibration of $\mathrm{C} 1$ and $\mathrm{C} 2$ segments of the left ICA was remarkable. The patient was diagnosed as left ICA dissection and anticoagulant therapy was initiated. A prominent improvement was noted in clinical findings during two months of followup period.
\end{abstract}

\section{Introduction}

Carotid artery dissection is characterized by the formation of mural hematoma as a result of rupture of tunica intima with an incidence of 2.5-3/100.000. It can develop spontaneously or secondary to trauma. Although postcoital artery dissections are rarely reported in the literature, any incident of postcoital carotid artery dissection in patients presented with isolated Horner syndrome has not been encountered so far $[1,2]$. A case with postcoital internal carotid artery (ICA) dissection in a patient referred with painful Horner syndrome is presented.

\section{Case Report}

A 40-year-old male patient was referred to our outpatient clinic with complaints of rapid onset of pain localized on behind his left eye during intercourse and subsequent development of ptosis of his left eyelid. Physical examination did not reveal any evidence of abnormality. In neurologic examination, semiptosis, enophthalmus, and myosis were observed on the left side. There was no sweating abnormality on his face. Ophthalmologic evaluation revealed normal visual acuity and intact fundi, bilaterally. There were no carotid bruits. He was smoking a pack per day for 20 years, without any history of alcohol and any known substance and drug abuse. Cranial magnetic resonance imaging (MRI) and craniocervical magnetic resonance angiography (MRA) were performed on the patient with diagnosis of left Horner syndrome. On diffusion MRI, any acute ischemic lesion was not detected. On T1-weighted and fat-suppressed cranial MRI, hyperintensity consistent with intramural hematoma was observed within cervical and temporal petrous segments of left ICA (Figures 1(a) and 1(b)). On cervical and cranial MRA, marked decrease in the calibration of $\mathrm{C} 1$, and $\mathrm{C} 2$ segments of the left ICA was remarkable (Figure 1(c)). Any abnormal contrast enhancement in cerebral parenchyma was not observed after administration of contrast material. Any abnormality in routine laboratory test and markers of vasculitis was not detected. The patient was diagnosed as left ICA dissection, and anticoagulant therapy was initiated. First intravenous heparin was given, and then warfarin was started. A prominent improvement was noted in clinical findings during two months of followup period.

\section{Discussion}

Horner syndrome manifests itself with signs of ptosis, myosis, enophthalmus, and facial anhidrosis. It is characterized 


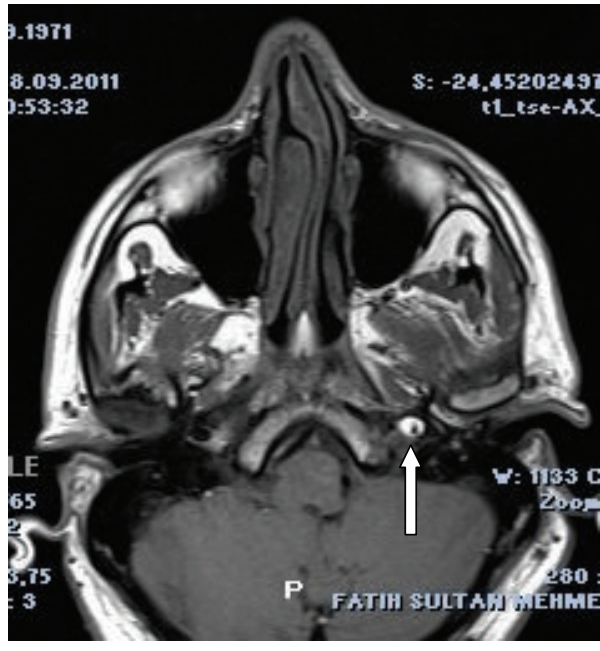

(a)

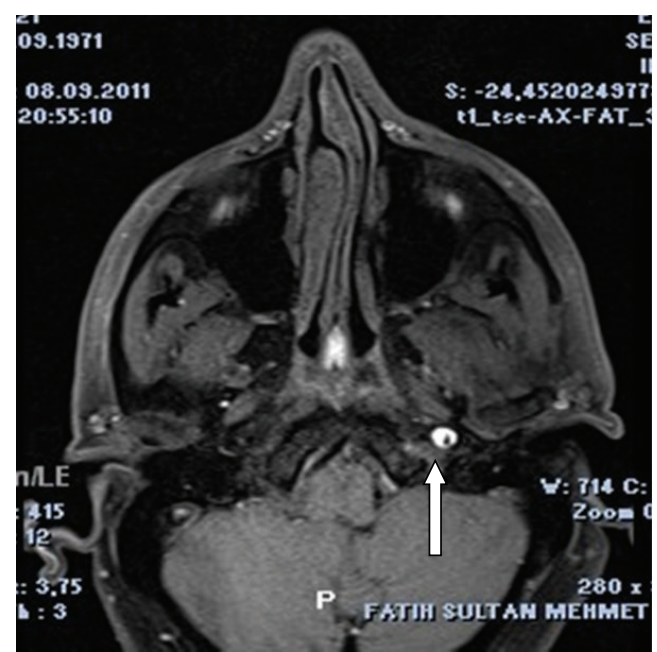

(b)

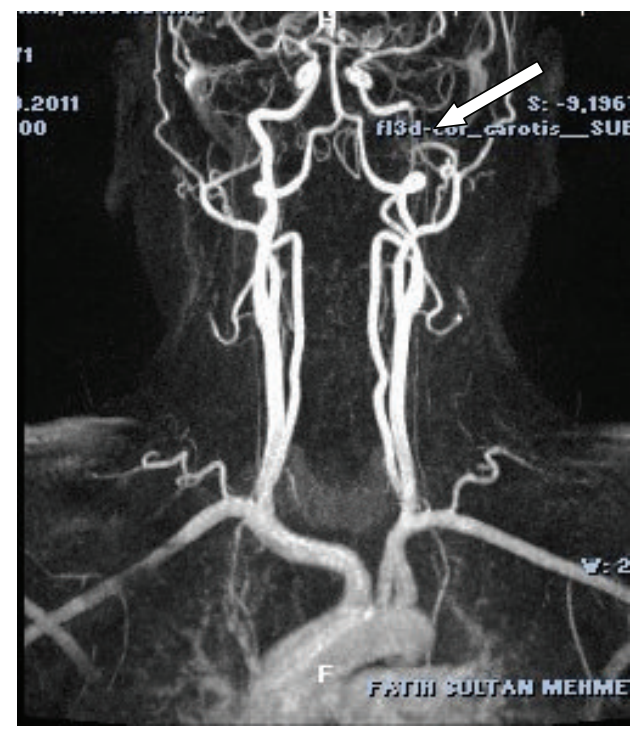

(c)

FIGURE 1: (a) Hyperintense area surrounding the left ICA on T1-weighted axial cranial MRI (white arrow). (b) Intramural hematoma on the left ICA on T1-weighted, fat-suppressed axial cranial MRI (white arrow). (c) Marked decrease in blood flow within cervical and temporal petrous segment of the left ICA on cervical MRA (white arrow).

by interruption of oculosympathetic pathway at any point between hypothalamus and the eye. Denervations of pupillary dilator and Muller muscle result in myosis and ptosis, respectively. Ciliospinal reflex is lost. Facial flushing can be seen. Since sympathetic fibers responsible for sudomotor innervation diverge from oculosympathetic pathway before superior cervical ganglion, anhidrosis is not seen in postganglionic lesions [3]. Horner syndrome can be classified in three groups according to the location of the lesion. Central type can occur in lesions of hypothalamus, brain stem, and medulla spinalis which affect descendant sympathetic pathways. Most frequently seen types are lateral medullary syndrome (Wallenberg syndrome) and syringomyelia. Other concomitant neurologic findings might suggest this type. Preganglionic type results from root avulsions in medulla spinalis, brachial plexus lesions, traumas, pulmonary, and mediastinal tumors (Pancoast syndrome: pulmonary apical tumors, and concomitant shoulder-arm pain). Postganglionic type is related to internal carotid artery diseases, basis cranii lesions, cavernous sinus diseases, superior orbital fissure, or orbital apex diseases [4].

Although patients with spontaneous ICA dissections frequently present with clinical manifestations of stroke, only $20 \%$ of the patients seek medical care with local complaints of head and neck pain, pulsatile tinnitus, and symptoms of isolated Horner syndrome. In the literature, in $91 \%$ of the cases with Horner syndrome developed secondary to ICA dissection, ipsilateral pains on neck and also headache have been reported. More rarely lower cranial nerve palsies can be seen $[5,6]$. In untreated cases, the risk of early onset of 
ischemic stroke within the first two weeks is increased. It is critically important to consider carotid dissection in the differential diagnosis of the patients presented with painful Horner syndrome in order to initiate therapy as soon as possible and also prevent potential onset of ischemic stroke. There is no clear data about preference of anticoagulant or antiplatelet treatments [7]. The choice of treatment should be made in individual basis.

\section{Conclusion}

Painful Horner syndrome with carotid artery dissection is a medical emergency in that carotid artery dissection is a serious consideration among its etiologic factors. In patients with Horner syndrome, attentive evaluation of medical history, physical, and radiological examination results is crucial so as to administer optimal and timely treatment and also prevent further deterioration of the patient's clinical state.

\section{Disclosure}

No benefits in any form have been received or will be received related directly or indirectly to the subject of this paper. The authors certify that all their affiliations with or financial involvement in, within the past 5 years and foreseeable future, any organization or entity with a financial interest in or financial conflict with the subject matter or materials discussed in the paper are completely disclosed (e.g., employment, consultancies, honoraria, stock ownership or options, expert testimony, grants or patents received or pending, and royalties). This paper has been approved by the authors. They certify that none of the materials in this paper have been published previously in any form, and none of these materials are currently under consideration for publication elsewhere.

\section{References}

[1] G. Y. Chang and P. C. Ahn, "Postcoital vertebral artery dissection," American Family Physician, vol. 54, no. 7, pp. 2195-2196, 1996.

[2] S. Prabhakaran and J. W. Krakauer, "Multiple reversible episodes of subcortical ischemia following postcoital middle cerebral artery dissection," Archives of Neurology, vol. 63, no. 6, pp. 891-893, 2006.

[3] Y. Almog, R. Gepstein, and A. Kesler, "Diagnostic value of imaging in Horner syndrome in adults," Journal of NeuroOphthalmology, vol. 30, no. 1, pp. 7-11, 2010.

[4] J. H. Lee, H. K. Lee, D. H. Lee, C. G. Choi, S. J. Kim, and D. C. Suh, "Neuroimaging strategies for three types of Horner syndrome with emphasis on anatomic location," American Journal of Roentgenology, vol. 188, no. 1, pp. 74-81, 2007.

[5] N. Kasravi, A. Leung, I. Silver, and J. G. Burneo, "Dissection of the internal carotid artery causing Horner syndrome and palsy of cranial nerve XII," Canadian Medical Association Journal, vol. 182, no. 9, pp. E373-E377, 2010.

[6] C. Tijssen and W. J. van Rooij, "Horner's syndrome and ipsilateral tongue paresis due to carotid artery dissection," Journal of Neurology, Neurosurgery and Psychiatry, vol. 78, no. 4, article 394, 2007.
[7] F. Kennedy, S. Lanfranconi, C. Hicks et al., "Antiplatelets versus anticoagulation for dissection: CADISS nonrandomized arm and meta-analysis," Neurology, vol. 79, pp. 686-689, 2012. 


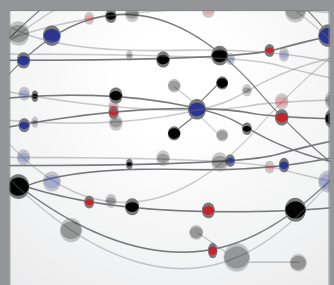

The Scientific World Journal
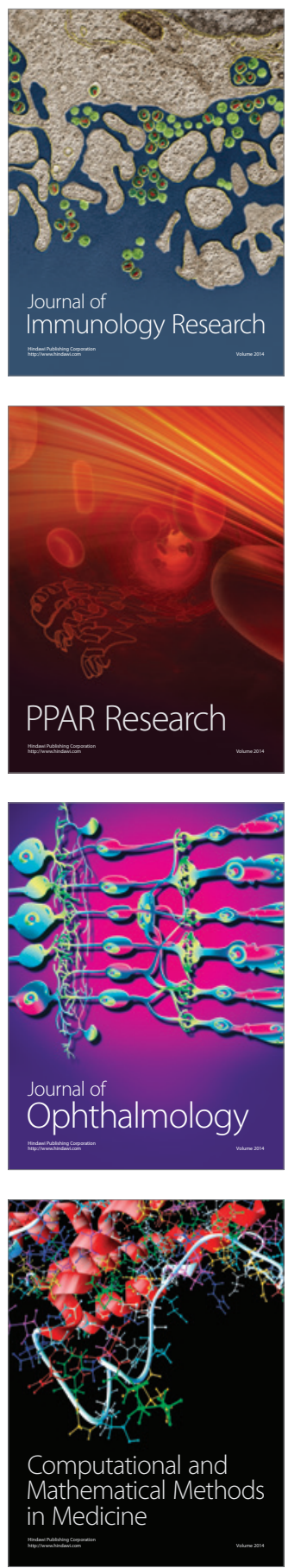

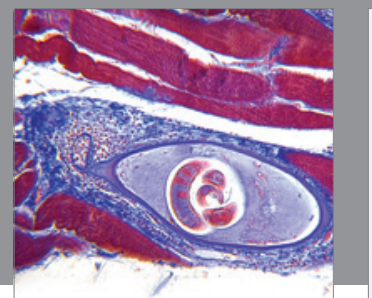

Gastroenterology

Research and Practice
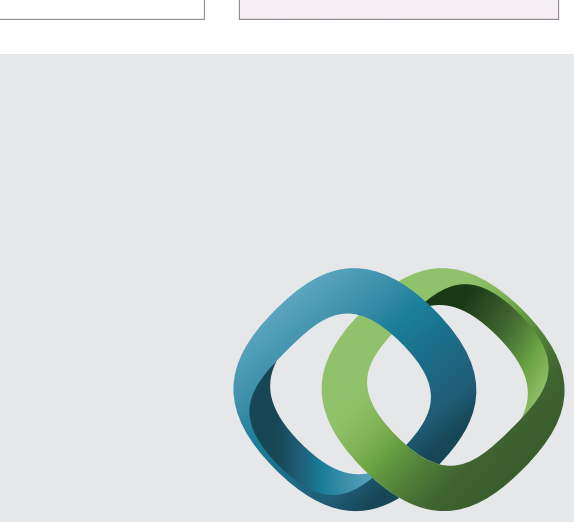

\section{Hindawi}

Submit your manuscripts at

http://www.hindawi.com
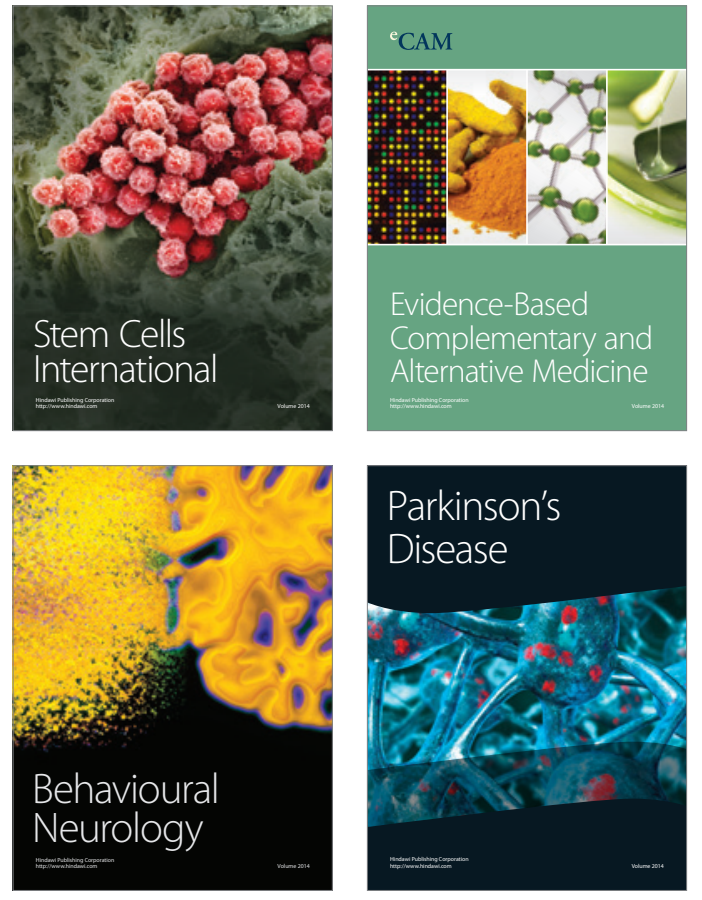
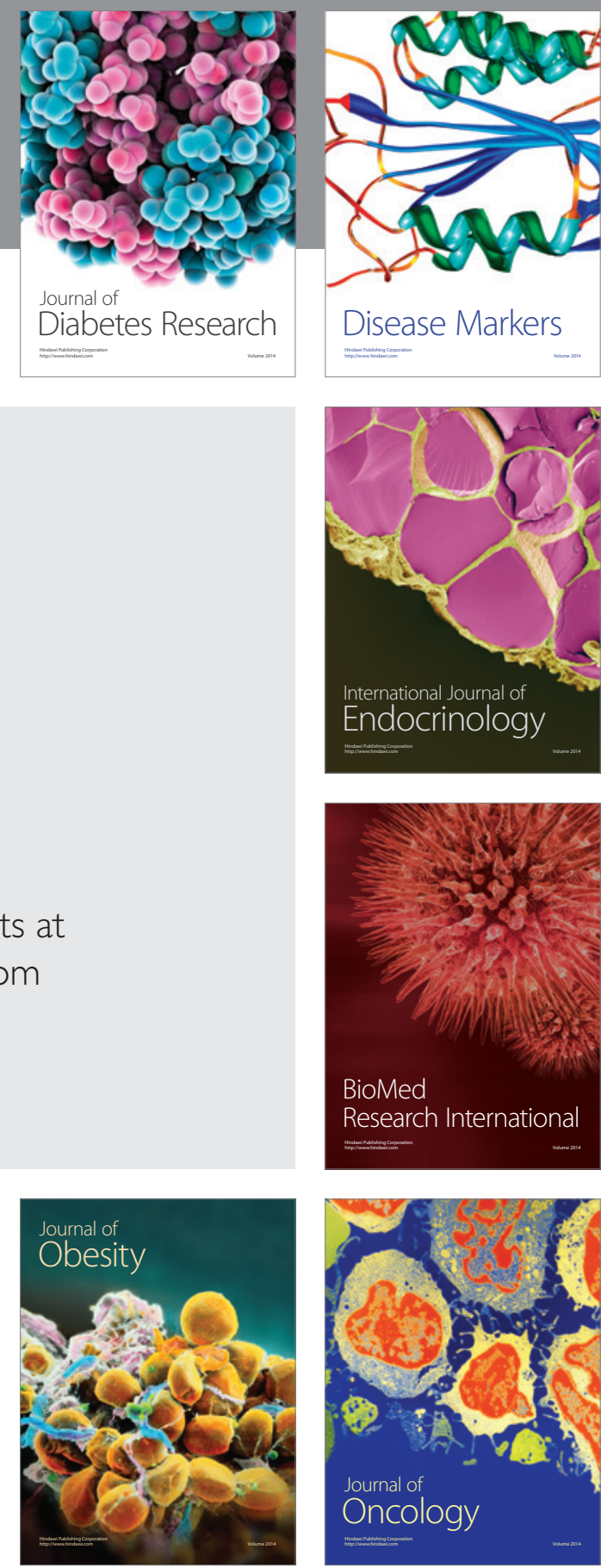

Disease Markers
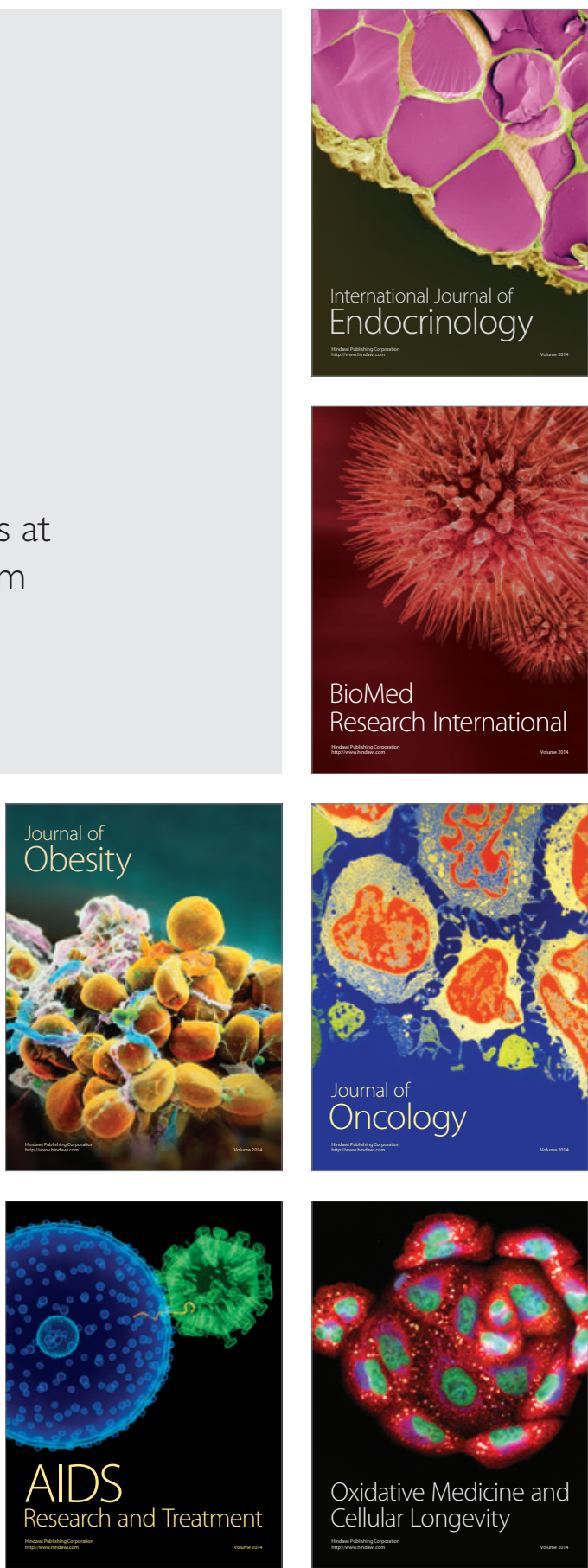